\title{
Evaluation of Genetic Diversity of Cercospora abelmoschi Infecting Okra in Guntur District, Andhra Pradesh, India
}

\author{
G. Amulya ${ }^{1 *}$, V. Prasanna Kumari ${ }^{1}$, V. Manoj Kumar ${ }^{1}$ and Y. Ashoka Rani ${ }^{2}$ \\ ${ }^{1}$ Department of Plant Pathology, ${ }^{2}$ Department of Crop physiology, Agricultural College, \\ Bapatla 522 101, A.P, India \\ *Corresponding author
}

\begin{abstract}
A B S T R A C T
Keywords

BamHI,

Cercospora, EcoRI,

Isolates, Okra,

Primers, Taq1,

Variability

Article Info

Accepted:

15 October 2018

Available Online:

10 November 2018

The present study was taken up in the Agricultural College, Bapatla during 2016-2017. Cercospora infected leaves were collected during kharif 2016 from eight different okra growing villages in Guntur district, Andhra Pradesh which were used for in planta isolation of fungal DNA and amplified using universal primers ITS 1 and ITS 4. The 550 bp amplicon thus obtained was restricted with hexa cutters, EcoRI, BamHI and tetra cutter Taq1 to find variability among Cercospora isolates. EcoRI found two restriction sites in all isolates except the Yazali isolate while BamHI found single restriction site in all the isolates with length polymorphism in Yazali isolate. Taq1 restriction indicated a high degree of genetic diversity among the isolates and was represented by three different banding patterns while in three isolates there were no restriction sites. Dendrogram constructed from similarity coefficients showed that Yazali isolate separated into a group upon digestion with EcoRI and BamHI while the Taq1 digestion of Yazali isolate clustered with Thimmareddipalem isolate. The results revealed that the presence of notable genetic variation in population sampled within the geographic region of Guntur district may be due to variations in single nucleotide polymorphism.
\end{abstract}

\section{Introduction}

Okra, Abelmoschus esculentus (L.) Moench, is an important warm season vegetable crop grown mainly in the tropical or sub-tropical regions during summer and rainy season (Thomson and Kelly, 1957).Okra was known to be originated from West Africa (Joshi et al., 1974). In India, it is grown in 503.7 thousand ha with a production of 5708 thousand $\mathrm{M} \mathrm{t}$ and $11.3 \mathrm{M} \mathrm{t} / \mathrm{ha}$ productivity. In Andhra Pradesh, it occupies an area of 18.6 thousand ha with a production of 211.2 thousand $\mathrm{M} \mathrm{t}$ and productivity is $11.4 \mathrm{M} \mathrm{t} / \mathrm{ha}$ (Ministry of Agriculture and Farmers Welfare, Govt. of India, 2014- 2015).

Okra crop suffers from number of biotic and abiotic stresses. Among biotic factors, fungal diseases are reported to pose serious problem in okra cultivation (Jha and Dubey, 2000). In India, two species of Cercospora viz., $C$. malayensis Stev. And Solh. And $C$. abelmoschi Ell. and Ev. were found to cause leaf spots in okra. These species differ in symptom production. Molecular phylogenetic 
techniques were used with the hope that they could more readily elucidate the phylogenetic relationships within the species. Hence, present investigation was undertaken with the objective to study the diversity of Cercospora abelmoschi infecting okra in Guntur district using ITS primers.

\section{Materials and Methods}

\section{Collection of diseased samples and In- Planta isolation of fungal DNA}

Cercospora infected leaves were collected during kharif 2016 from eight different okra growing villages in Guntur district, Andhra Pradesh and were designated as described in the Table 1. The samples were screened for the diseased portion, required amount of leaf was weighed, properly labeled, packed in polythene bags and stored at $-40^{\circ} \mathrm{C}$ temperature for further investigations. Plant DNA was isolated by modified CTAB method (Murray and Thompson, 1980). The concentration of DNA was determined using the Nano-Drop ND-1000 spectrophotometer (Nano Drop Technologist). In-planta expression of pathogenic DNA was tested as the technique avoids the usage of liquid nitrogen, its simplicity, low cost, fast and safe protocol.

\section{PCR amplification with ITS primers}

Amplification of Internal Transcribed Spacer (ITS) region using universal primers previously described by White et al. (1990). Forward and reverse primers, viz., ITS1 (5' TCCGTAGGTGAACCTGCGG 3') and ITS 4 (5' TCCTCCGCTTATTGATATGC 3') respectively, synthesized based on conserved $18 \mathrm{~S}$ and $28 \mathrm{~S}$ coding regions of the nuclear rDNA were used. Amplification was carried out with $25 \mu$ reaction mixture containing 2.5 $\mu l$ of 10X PCR buffer, $0.5 \mu 110 \mathrm{mMdNTPs}, 1$ $\mu \mathrm{l}$ of each primer, $1.5 \mu \mathrm{l}$ of $25 \mathrm{mM} \mathrm{MgCl}_{2}, 0.5$ units of Taq polymerase, $15 \mu \mathrm{l}$ of water and $3 \mu \mathrm{l}$ of template DNA. Amplification was performed in $0.2 \mathrm{ml}$ thin walled PCR tubes using a thermocycler (Biorad) programmed for initial denaturation at $94^{\circ} \mathrm{C}$ for $5 \mathrm{~min}$, followed by 35 cycles of denaturation at $94^{\circ} \mathrm{C}$ for $30 \mathrm{sec}$, annealing at $56.9^{\circ} \mathrm{C}$ for $1 \mathrm{~min}$, primer extension at $72^{\circ} \mathrm{C}$ for $1.5 \mathrm{~min}$ and a final extension at $72^{\circ} \mathrm{C}$ for $7 \mathrm{~min}$ and hold at $4^{0} \mathrm{C}$. Amplified products were analysed in $1 \%$ agarose gel and the migration pattern of the DNA fragments in the gel was recorded using gel documentation system (Biorad, USA) in an auto exposure mode.

\section{Restriction Enzyme Analysis of ITS regions}

Polymorphism was determined by digesting the amplicon obtained using ITS primers with three different restriction endonucleases, i.e., hexa basepair cutters - EcoRI, BamHI and tetra basepair cutter - TaqI. The restriction fragments were size separated by electrophoresis on $2.0 \%$ agarose gel and were viewed under UV light and phylogenetic analysis was done using the Dendro-UPGMA (Unweighted Pair Group Method with Arithmetic mean) (Garcia-Vallve et al., 1999) software. Restriction bands were analysed, wherein each band with a different electrophoretic mobility was assigned a position number and based on the presence or absence of the band it was named as binary digits 1 or 0 . Only reproducible bands were considered for analysis. Bands common to all isolates were incorporated into the analysis. Based on the similarity coefficients, a dendrogram was constructed by the unweighted pair group method with arithmetic mean (UPGMA) hierarchical clustering algorithm.

\section{Results and Discussions}

The DNA extracted (Plate 1) from Cercospora infected leaf samples were amplified and 
amplicon of $550 \mathrm{bp}$ in all the samples (Plate 2) confirmed that the quality of DNA extracted using the protocol was suitable for the purpose. No size variation was found among the amplified ITS regions. The two hexa cutter restriction endonucleases EcoRI and BamHI tested, showed restriction sites in the ITS region and revealed polymorphism in only one isolate collected from Yazali. Seven isolates tested with EcoRI enzyme produced three digested products at 550, 450 and $200 \mathrm{bp}$ products (Plate 3). BamHI also gave similar variation in the restriction site with Yazali isolate where only one digested product at 450 bp was observed as against two in other isolates (Plate 4).

Based on the dendrogram construction utility software DendroUPGMA, the similarity coefficients were transformed into distances and clustering was done using the Unweighted Pair Group Method with Arthmetic mean (Garcia-Vallve et al., 1999). The dendrogram constructed indicated that the Yazali isolate differed in restriction digestion. EcoRI restriction resulted in three fragments in all seven isolates except the isolate collected from Yazali due to difference in restriction sites (Fig. 1). Restriction with BamHI exhibited single restriction site in all seven isolates except in isolate from Yazali which differed in length polymorphism (Fig. 2).

Restriction with tetra base pair cutter Taq1 indicated a high degree of genetic diversity among the isolates of okra collected from different geographical locations in the study which was represented by the differences in banding pattern. Based on similarity coefficients, two major clusters were formed which further divided into four groups (Fig. 3). Bapatla 1 and Dhundivaripalem 3 isolates had similar banding patterns with six restriction sites that were clustered into a group. The isolates Nandirajuthota, Dhundivaripalem 1 and Dhundivaripalem 2 did not have any restriction sites for tetra cutter Taq1, thus were grouped together. Isolate Bapatla 2 had only one restriction site and was separately grouped whereas the isolates Yazali, Thimmareddipalem had three restriction sites and were in a group (Plate 5).

Table.1 Okra samples collected from different locations of Guntur district

\begin{tabular}{|c|l|c|}
\hline S. No. & Place of collection & Sample designation \\
\hline $\mathbf{1}$ & Bapatla & $\mathrm{Bpt} 1$ \\
\hline $\mathbf{2}$ & Bapatla & $\mathrm{Bpt} 2$ \\
\hline $\mathbf{3}$ & Nandirajuthotha & $\mathrm{Nt}$ \\
\hline $\mathbf{4}$ & Dhundivaripalem & $\mathrm{Dp} 1$ \\
\hline $\mathbf{5}$ & Dhundivaripalem & $\mathrm{Dp} 2$ \\
\hline $\mathbf{6}$ & Dhundivaripalem & $\mathrm{Dp} 3$ \\
\hline $\mathbf{7}$ & Yazali & $\mathrm{Yz}$ \\
\hline $\mathbf{8}$ & Thimmareddipalem & $\mathrm{Tp}$ \\
\hline
\end{tabular}




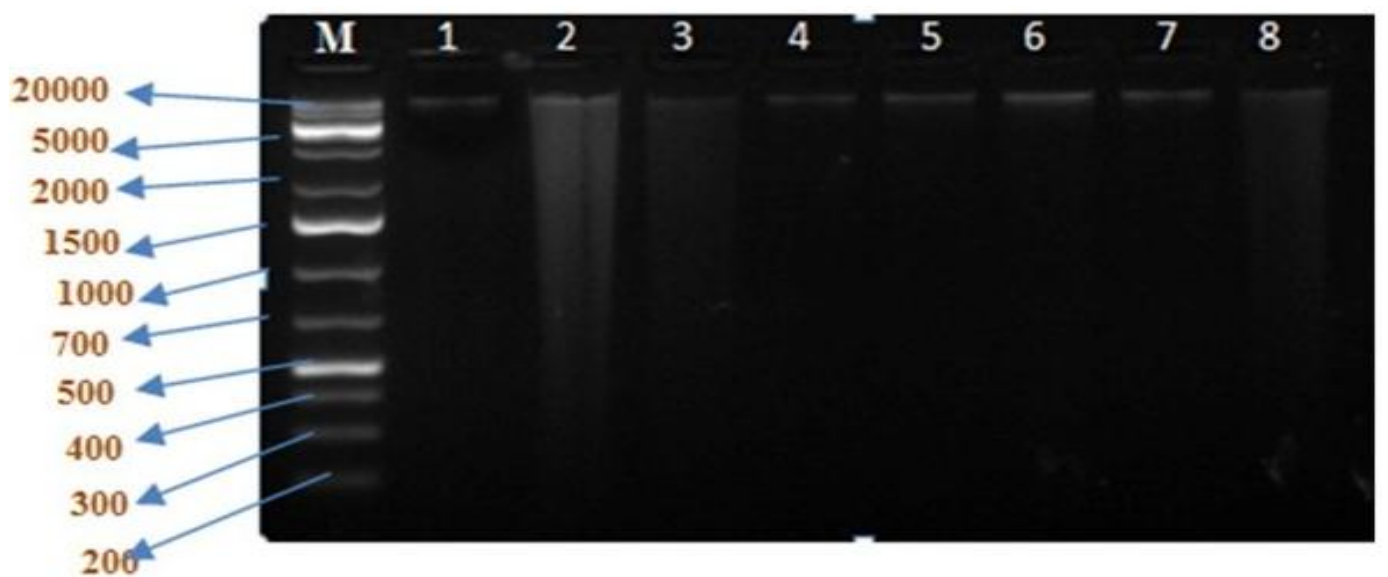

Plate.1 Agarose gel electrophoresis showing DNA of Cercospora abelmoschi isolated from infected leaves. Lanes 1-8 represent isolates Bpt1, Bpt2, Nt, Dp1, Dp2, Dp3,Yz, Tp. Lane M indicates the molecular weight marker $1 \mathrm{~kb}$ plus ladder

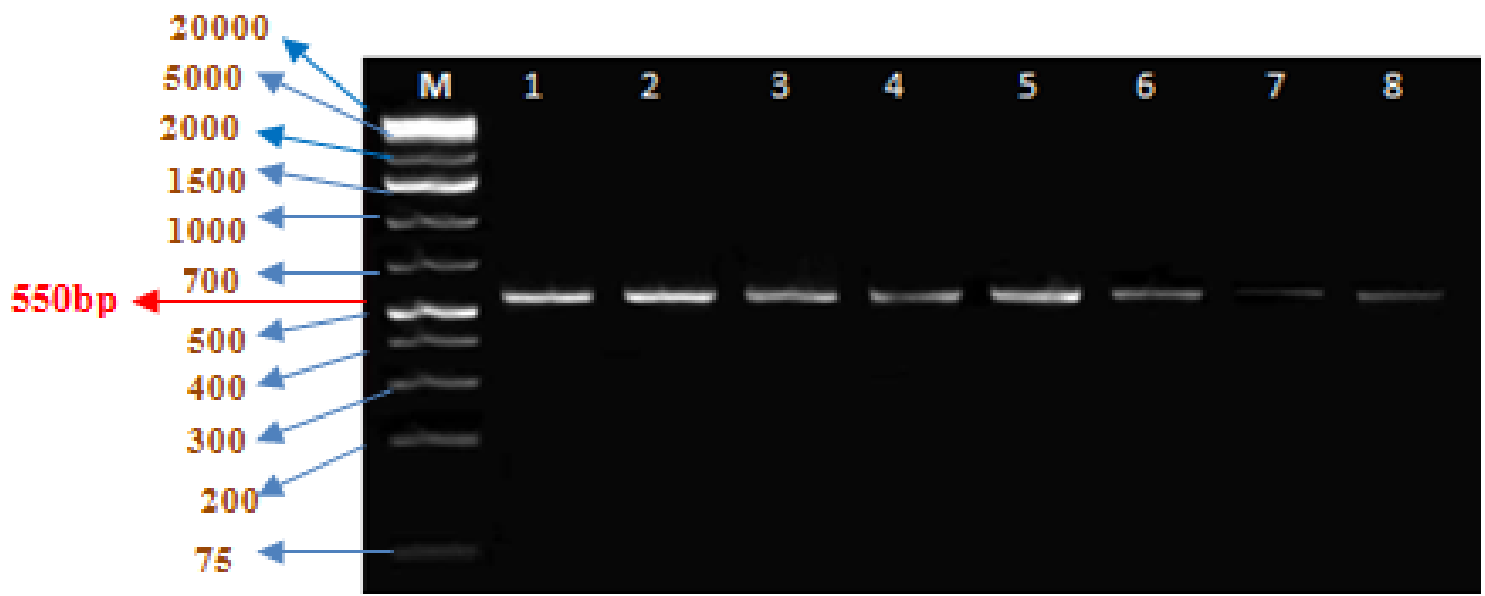

Plate.2 Agarose gel electrophoresis showing amplicon amplified by universal Internal Transcribed Spacer (ITS) primers in eight isolates. Lanes 1-8 represent isolates Bpt1, Bpt2, Nt,

Dp1, Dp2, Dp3, Yz, Tp. Lane M indicates the molecular weight marker 1kb plus ladder

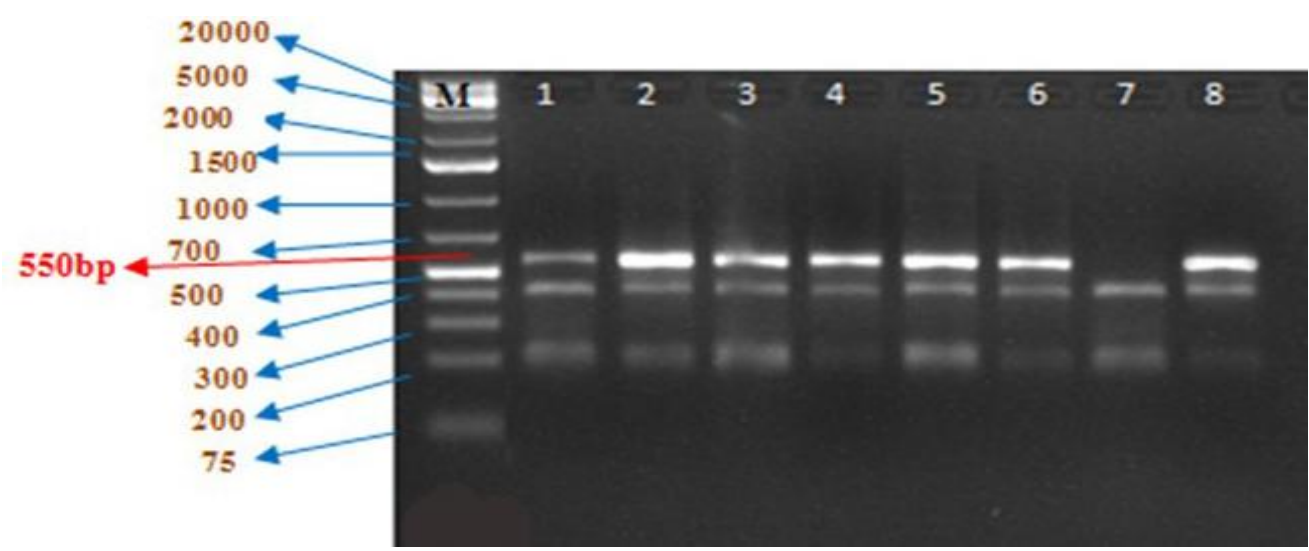

Plate.3 Restriction analysis of amplicons obtained from ITS primers with EcoRI. Lanes 1-8: Digested products of ITS region from isolates Bpt1, Bpt2, Nt, Dp1, Dp2, Dp3, Yz, Tp. Lane M indicates the molecular weight marker $1 \mathrm{~kb}$ plus ladder 


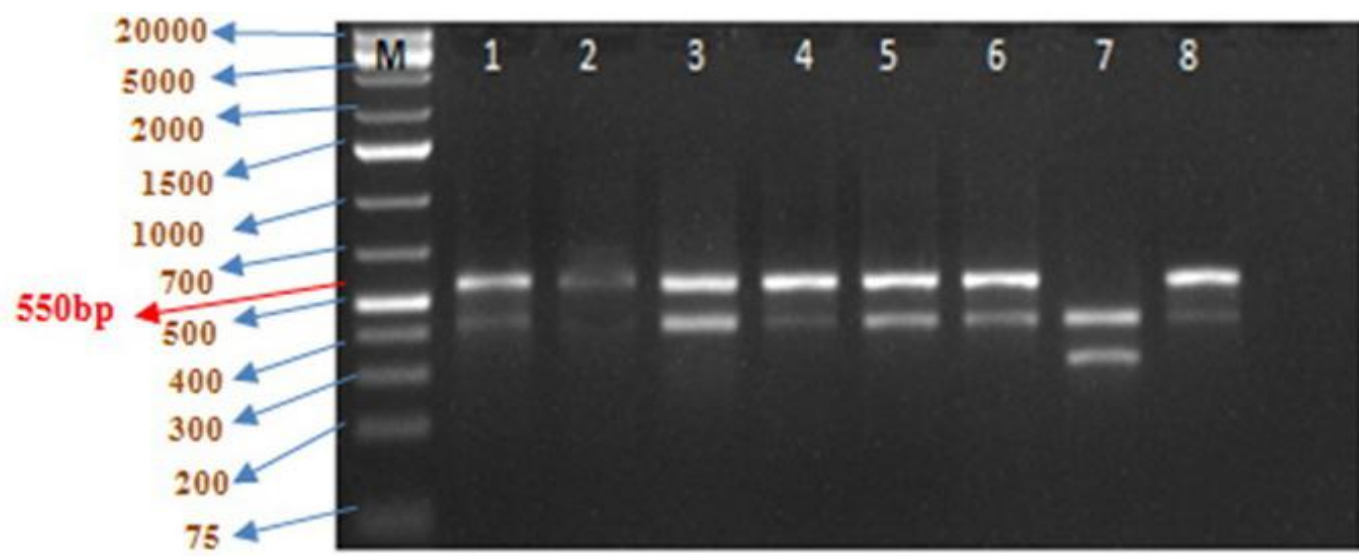

Plate.4 Restriction analysis of amplicons obtained from ITS primers with BamHI. Lanes 1-8: Digested products of ITS region from isolates Bpt1, Bpt2, Nt, Dp1, Dp2, Dp3, Yz, Tp. Lane M indicates the molecular weight marker $1 \mathrm{~kb}$ plus ladder

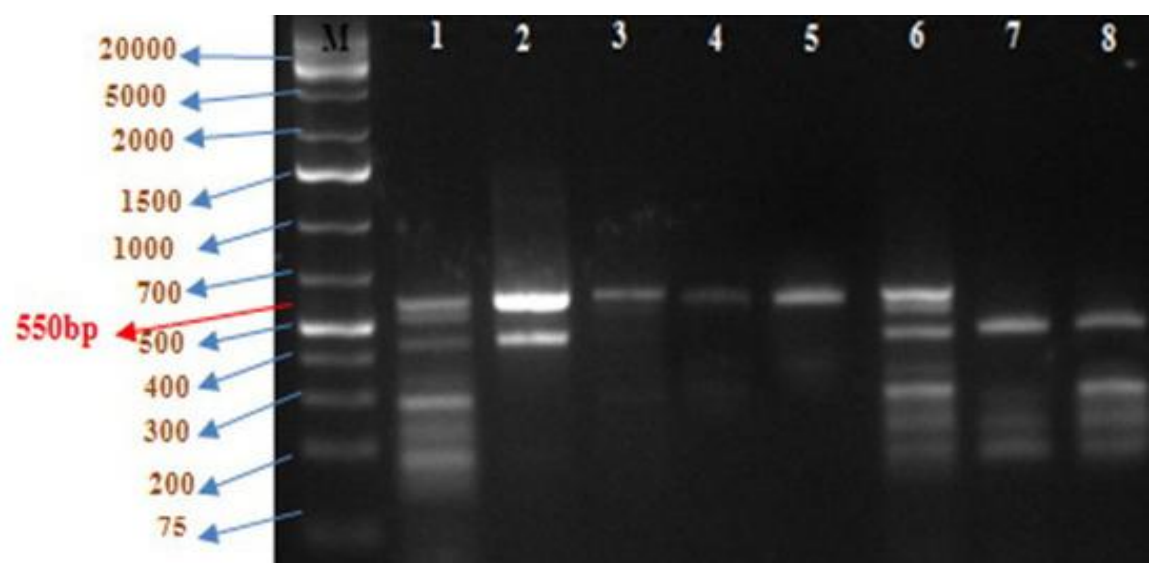

Plate.5 Restriction analysis of amplicons obtained from ITS primers with Taq1. Lanes 1-8: Digested products of ITS region from isolates Bpt1, Bpt2, Nt, Dp1, Dp2, Dp3, Yz, Tp. Lane M indicates the molecular weight marker $1 \mathrm{~kb}$ plus ladder

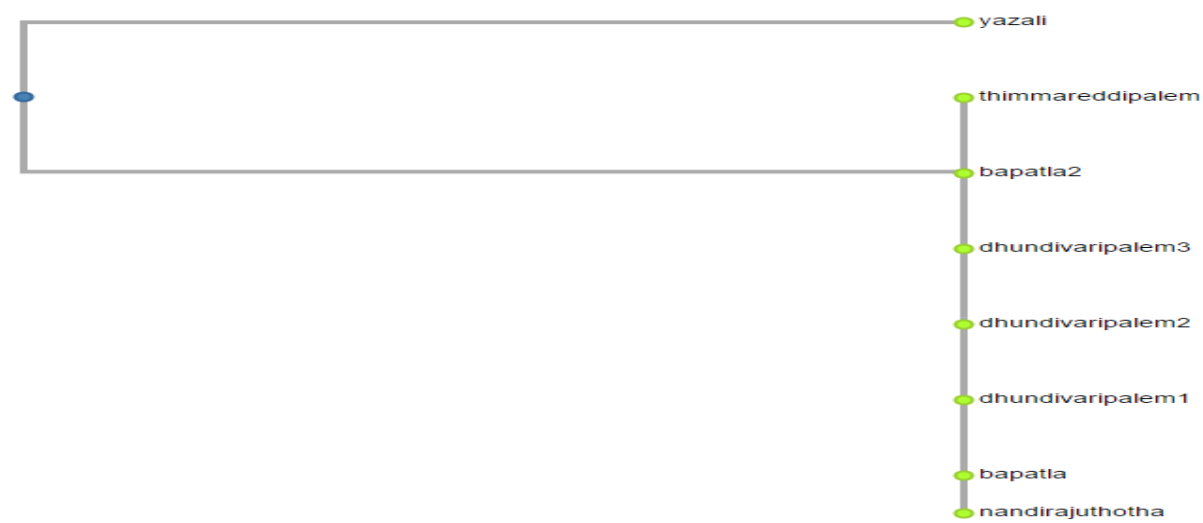

Fig.1 Dendrogram showing clustering pattern of Cercospora isolates using EcoRI by UPGMA method 


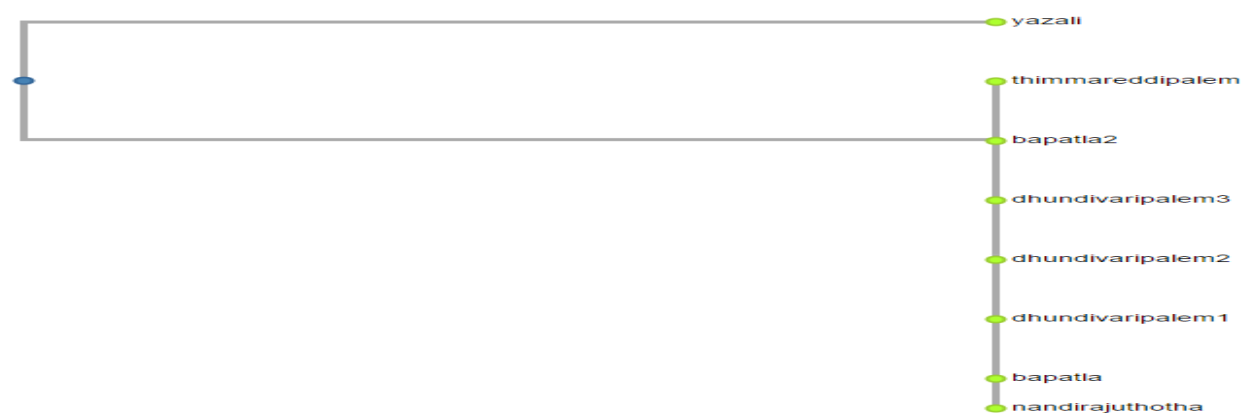

Fig.2 Dendrogram showing clustering pattern of Cercospora isolates using BamHI by UPGMA method

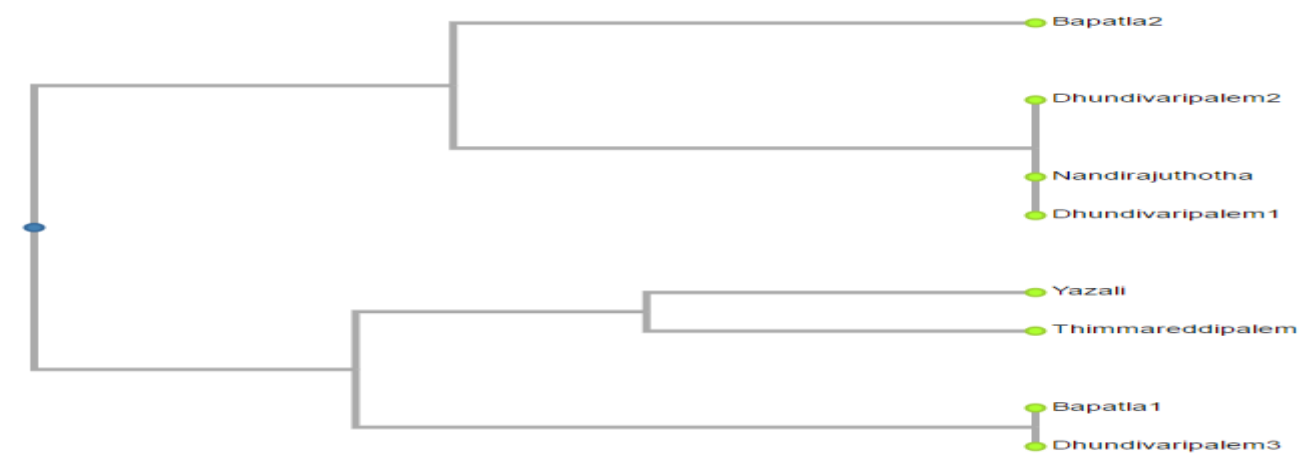

Fig.3 Dendrogram showing clustering pattern of Cercospora isolates using Taq1 by UPGMA method

The present results were in agreement with the similar study conducted on ectomycorrhizal fungi in Fennoscandia that showed intra specific polymorphism in seven species. The polymorphism was reported due to length mutations, ranging from 5 to $15 \mathrm{bp}$ in four of the seven polymorphic species (Karen et al., 1997). There are reports on host- specific specialization (formaespeciales) of $C$. canescens from V. mungo (Kaushal et al., 1993) and $V$. radiate (Chand et al., 2000). Genetic heterogeneity previously has been observed for other fungi like Ascochyta rabiei (Morjane et al., 1994) and Rhynchosporium secalis (Dermott et al., 1989). In case of A. rabiei, population sampled from a single chickpea field contained a large amount of subtle genetic variation, with more than one $A$. rabiei haplotype being present on single host plant even with in single lesion.

In the present study, it is confirmed that variability existed in Cercospora isolates collected from Guntur district. The different banding patterns with hexa and tetra cutters revealed that polymorphism existed within the isolates which may be due to variations in single nucleotide resulting in variation in restriction sites.

The present results were in agreement with the similar study conducted on ectomycorrhizal fungi in Fennoscandia that showed intra specific polymorphism in seven species. The polymorphism was reported due to length mutations, ranging from 5 to $15 \mathrm{bp}$.

in four of the seven polymorphic species (Karen et al., 1997). There are reports on host- specific specialization (formaespeciales) of $C$. canescens from V. mungo (Kaushal et al., 1993) and V. radiate (Chand et al., 2000). Genetic heterogeneity previously has been observed for other fungi like Ascochyta rabiei (Morjane et al., 1994) and Rhynchosporium secalis (Dermott et al., 1989). In case of A. rabiei, 
population sampled from a single chickpea field contained a large amount of subtle genetic variation, with more than one $A$. rabiei haplotype being present on single host plant even with in single lesion.

In the present study, it is confirmed that variability existed in Cercospora isolates collected from Guntur district. The different banding patterns with hexa and tetra cutters revealed that polymorphism existed within the isolates which may be due to variations in single nucleotide resulting in variation in restriction sites.

\section{References}

Chand, R., Lal, M and Chaurasia, S. 2000. Formaespecialis in Cercospora canescens. In Proceedings of the International Conference on Integrated Plant Disease Management for Sustainable Agriculture, Indian Phytopathological Society. 1: 164-165.

Dermott, M. J. M., Mc Donald, B. A., Allard, R. W and Webster, R. K. 1989. Genetic variability for pathogenicity, isozyme, ribosomal DNA and colony color variants in populations of Rhynchosporium secalis. Genetics. 122: 561-565.

Garcia-Vallve, S., Palau, J and Romeu, A. 1999. Horizontal gene transfer in glycosyl hydrolases inferred from codon usage in Escherichia coli and Bacillus subtilis. Molecular Biology and Evolution. 16 (9): 1125-1134.

Jha, A.K and Dubey, S.G. 2000. Occurrence of collar rot of (Abelmoschus esculentus) in the plateau region of Bihar. Journal of Research-Birsa Agricultural University. 12(1): 67-72.

Joshi, A.B., Gadwal, V.R and Hardas, M.W.
1974. Evolutionary studies in world crops. In J.B. Hutchinson (ed.) - Diversity and Change in the Indian Subcontinent, Cambridge.99-110.

Karen, O., Hogberg, N., Jonsson, L and Nylund, J. E. 1997. Inter- and intraspecific variation in the ITS region of rDNA of ectomycorrhizal fungi in Fennoscandia as detected by endonuclease analysis. New Phytologist. 136: 313-325.

Kaushal, R. P. and Singh, B. M. 1993.Pathogenic variability in leaf spot and powdery mildew pathogens of legumes. Indian Phytopathology. 46: 182-184.

Ministry of Agriculture and Farmers Welfare, Govt. of India, 2014- 2015.Agricultural Statistics at a Glance.204-209.Bawden, F.C. 1999.Plant Diseases. Green World publishers, Lucknow, India. 206.

Morjane, H., Geistlinger, J., Harrabi, M., Weising, K and Kahl, G. 1994. Oligonucleotide fingerprinting detects genetic diversity among Ascochyta rabiei from a single chickpea field in Tunisia. Current Genetics. 26: 191-197.

Murray, M.G and Thompson, W.F. 1980. Rapid isolation of high molecular weight plant DNA. Nucleic Acids Research. 8: 43214326.

Thomson, K.F and Kelly, C.W. 1957. Vegetable Crops. McGraw Hill Book Co, Inc. USA. 164-169.

White, T.J., Bruns, T., Lee, S and Taylor, J. 1990.Amplification and direct sequencing of fungal ribosomal RNA genes for Phylogenetics. In M.A. Innis, D.H. Gelfand, and J.J. Sninsky (eds.) - PCR Protocols: A Guide to Methods and Applications. Academic Press, New York. Pp. 315-322.

\section{How to cite this article:}

Amulya, G., V. Prasanna Kumari, V. Manoj Kumar and Ashoka Rani, Y. 2018. Evaluation of Genetic Diversity of Cercospora abelmoschi Infecting Okra in Guntur District, Andhra Pradesh, Inda. Int.J.Curr.Microbiol.App.Sci. 7(11): 1925-1931.

doi: https://doi.org/10.20546/ijcmas.2018.711.218 